\title{
Numerical Model and Forecasting Potential of Aircraft Weather Hazards over Kenya
}

\author{
Francis Jagero \\ Department of Meteorology, University of Nairobi, Nairobi, Kenya \\ Tel: 254-720-807-037Ｅ-mail: jagerof2017@gmail.com
}

Received: November 21, 2017 Accepted: January 22, 2018 Published: January 24, 2018

Doi: 10.5296/ijca.v2i1.12528ＵRL: https://doi.org/10.5296/ijca.v2i1.12528

\begin{abstract}
The study investigated the forecasting potential of aircraft weather hazards over Kenya using numerical model. The various causes of accidents/incidents were identified using analyzed investigated weather-related aviation hazards data obtained from Kenya Civil Aviation Authority database system from 2008 through 2014. The parameters analyzed included the Winds, Temperature, Relative humidity, Convective Available Potential Energy (CAPE), Lifted Index (LI) and Dew Point Temperature. Their combined effect was able to provide the means of identifying the areas of strong convection. The model was run on a grid point distance resolution of $10 \mathrm{~km}$ and runs finite differencing scheme, based on Taylor series. Grid Analysis and Display System (GrADS) which is embedded on the model upon installation, was used as the default post processing tool. Key findings revealed that Wind, Fog, Turbulence, Heavy rain showers, and low ceiling influenced aircraft operations. It was shown that the majority of the hazards were linked with cumulonimbus clouds. Landing phase of flight affected aviation most.
\end{abstract}

Keywords: Aircraft, Forecasting potential, Numerical model, Weather hazards

\section{Introduction}

Aviation hazards during the cumulus stage of thunderstorms are mainly caused by supercooled water (Okoola, 2005). Hazards during the mature stage of the thunderstorms are due to strong winds, lightning and precipitation, while those in the final stage arise from downbursts. Thunderstorms are produced by convective instability, moisture, and a source of lift. In forecasting thunderstorms, it is important to know whether they will occur; their severity; the associated severe phenomena; and the type of storm likely to be observed.

The research problem was based on Annex 13 - Aircraft Accident and Incident Investigation that was developed by ICAO (International Civil Aviation Organization). According to the 


\section{Macrothink}

provisions laid down in ICAO Annex 13 to the International Civil Aviation Convention Aircraft Accident and Incident Investigation, the sole objective of the investigation of an accident or incident is to prevent accidents and incidents.

Even though air navigation is considered to be the safest means of transport, it is an activity facing many potential dangers that include weather-related ones. The research intends to address the dangers that are influenced by weather hazards through forecasting using Weather Research and Forecasting (WRF) Model. The aim is to provide timely advisories to aviation stakeholders.

\section{Conceptual Framework}

Figure 1 shows the summary of the concept behind the study. The figure highlights data extracted for the study, the methods applied to achieve the major outcome as well as dependent, independent, and intervening variables. This provides the rationale for selection of the study and contribution to research and planning- relationships between methods, factors, and outputs are demonstrated.

Meteorological expert services-forensic meteorology, are provided through observation, analysis, and forecasting to the International, Regional, and National aviation authorities their aim is policy and management. The key weather phenomena that influenced accidents/incidents were identified. This information is important to aviation stakeholders for better policy and planning, route mapping, operation schedule, and improved aviation meteorological services. Planning leads to enhanced safety, enhanced profit, and improved livelihood- economic benefit. 


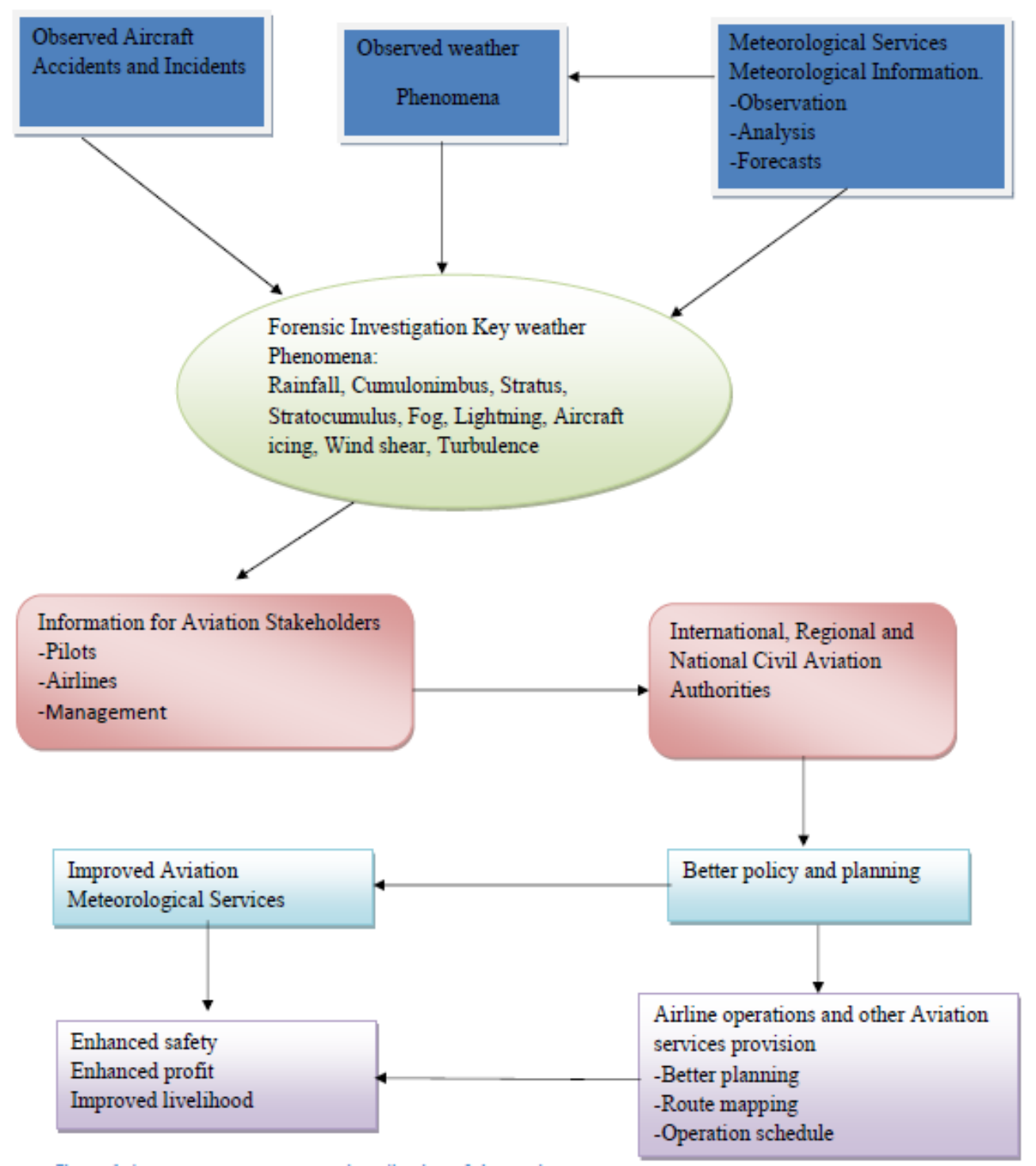

Figure 1. Input, process, output and application of the study

\section{Data and Methods}

\subsection{Data}

The types of data source are discussed in this subsection.

3.1.1 Data of the Weather-related Hazards that Lead to Aviation Incidents/Accidents

The aviation weather-related accident/incident data were obtained from Kenya Civil Aviation Authority (KCAA) database from 2008 through 2014.A total of 8 cases of accidents/incidents occurred over Kenyan airspace within this period and they were caused by weather hazards.

All accidents and serious incidents conformed to the definition within the $9^{\text {th }}$ edition of the Convention on International Civil Aviation Annex 13 (International Civil Aviation Organization, 2001). There were 8 different types of aircrafts in the accidents/incidents analyzed including commercial airplanes and helicopters. 


\section{Macrothink}

Area of Study

Kenya boasts of six airports, two military airbases, and several airstrips located in the 47 counties. Figure 2 shows the study area.

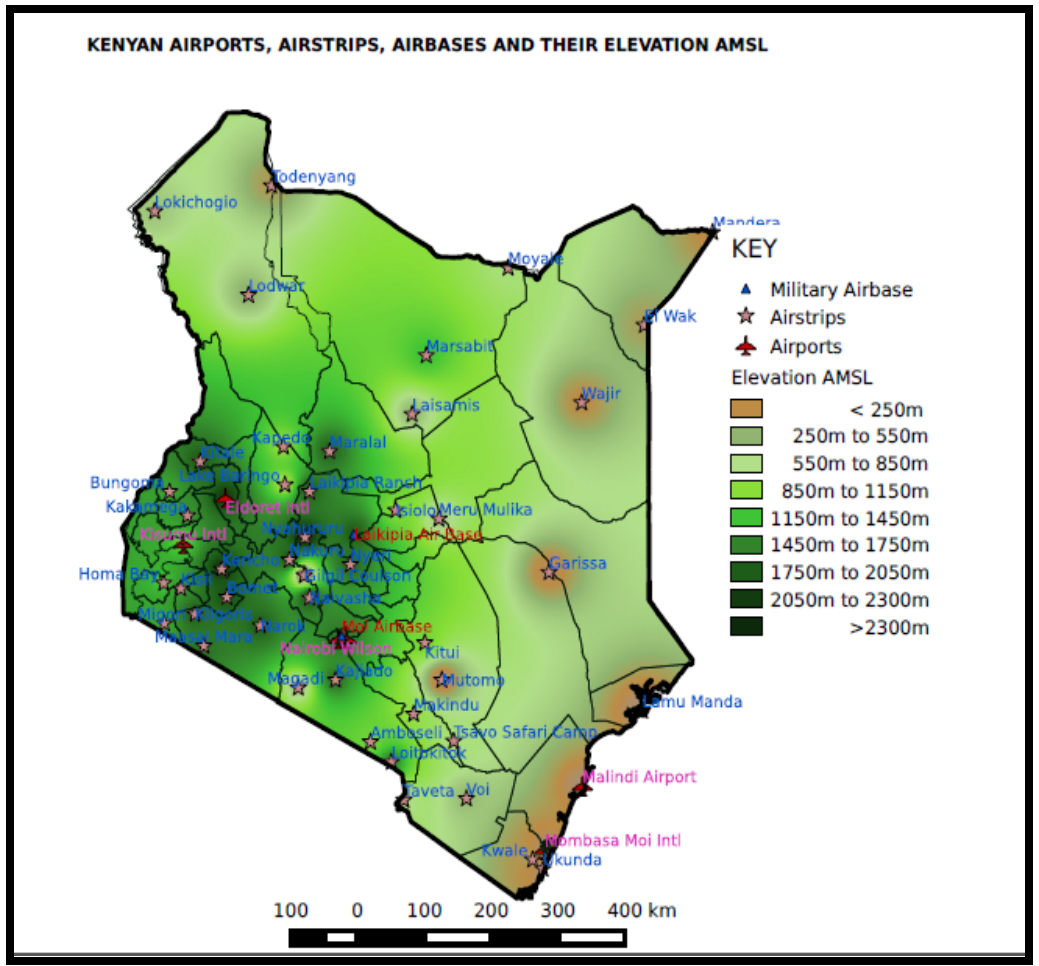

Figure 2. Map of Kenya, showing Airports, Airstrips, Airbases and Topography.

Source: Generated using Q-GIS

Table 1. Major airports and airbases in Kenya

\begin{tabular}{llllll}
\hline Airports & Latitude & Longitude & Airbase & Latitude & Longitude \\
\hline Kisumu & -0.09 & 34.73 & Laikipia & 0.033 & 37.027 \\
Moi Intl & -4.04 & 39.59 & Moi Airbase & -1.278 & 36.862 \\
Wilson & -1.32 & 36.82 & & & \\
Jomo Kenyatta & -1.32 & 36.93 & & & \\
Eldoret & 0.5 & 35.3 & & & \\
Malindi & -3.22 & 40.1 & & & \\
\hline
\end{tabular}


Table 2. Airstrips in Kenya

\begin{tabular}{|c|c|c|c|c|c|}
\hline Airstrip & Latitude & Longitude & Airstrip & Latitude & Longitude \\
\hline Wajir & 1.73 & 40.09 & Lamu Manda & -2.25 & 40.91 \\
\hline Laikipia Ranch & 0.58 & 36.43 & Lodwar & 3.12 & 35.61 \\
\hline Tsavo Safari Camp & -2.64 & 38.37 & Loitokitok & -2.91 & 37.53 \\
\hline Amboseli & -2.65 & 37.25 & Lokichogio & 4.2 & 34.35 \\
\hline Bomet & -0.78 & 35.32 & Magadi & -1.95 & 36.28 \\
\hline Bungoma & 0.58 & 34.55 & Makindu & -2.29 & 37.83 \\
\hline El Wak & 2.73 & 40.93 & Mandera & 3.93 & 41.85 \\
\hline Garissa & -0.46 & 39.65 & Maralal & 1.1 & 36.7 \\
\hline Gilgil Coulson & -0.5 & 36.36 & Marsabit & 2.34 & 38 \\
\hline Homa Bay & -0.6 & 34.47 & Migori & -1.12 & 34.48 \\
\hline Kajiado & -1.85 & 36.78 & Moyale & 3.47 & 39.1 \\
\hline Kakamega & 0.27 & 34.79 & Meru Mulika & 0.23 & 38.17 \\
\hline Kapedo & 1.16 & 36.08 & Mutomo & -1.85 & 38.21 \\
\hline Kericho & -0.42 & 35.25 & Naivasha & -0.79 & 36.43 \\
\hline Kilgoris & -1 & 34.89 & Nakuru & -0.3 & 36.16 \\
\hline Kisii & -0.67 & 34.7 & Narok & -1.15 & 35.77 \\
\hline Kitale & 0.97 & 34.96 & Nyahururu & -0.01 & 36.37 \\
\hline Kitui & -1.37 & 37.98 & Nyeri & -0.36 & 36.98 \\
\hline Kwale & -4.17 & 39.43 & Taveta & -3.4 & 37.7 \\
\hline Laisamis & 1.58 & 37.81 & Todenyang & 4.53 & 35.92 \\
\hline Lake Baringo & 0.67 & 36.1 & Voi & -3.38 & 38.54 \\
\hline Ukunda & -4.29 & 39.57 & Isiolo & 0.34 & 37.59 \\
\hline Maasai Mara & -1.41 & 35.01 & & & \\
\hline
\end{tabular}

3.1.2 The Data for Determining the Spatial Distribution of Cloud Cover

Satellite data were used in this study. The satellite data include the Meteosat Second Generation data displayed on the Synergie at the Kenya Meteorological Department (KMD), a production of the French MeteoFrance. In it, several metrological products are availed: Satellite imagery from the United States Of America (USA ) Geostationary Operational Environmental Satellite West

(GOESW) and East satellites, Red Green Blue (RGB) Composite products for various products, Meteorological Products Extraction Facility (MPEF) products from Meteosat Second Generation(MSG), Aerie weather Models amongst others. In the Synergize, it has 
been made possible that at every 15 minutes, data is downloaded, saved, and processed for viewing and analysis by the Forecasters on duty.

\subsubsection{Data Used to forecast Cumulonimbus Clouds}

The Weather Research and Forecasting (WRF) Model, is a consortium of the USA based Global Forecasting System (GFS). The GFS is a Global Circulation Model (GCM) at 50km resolution that integrates global observational and satellite data to produce forecasts. WRF, as used in KMD, is a subset of the GFS GCM model, in that it picks its pre-fixed static and initial boundary conditions from the GFS.

The WRF model was run on a grid point distance resolution of $10 \mathrm{~km}$. WRF runs finite differencing scheme, based on Taylor series. The length of the run was 48hours, beginning from 14 ${ }^{\text {th }}$ April, 2017, 0000Z to $16^{\text {th }}$ April 2017, and 0000Z. Grid Analysis and Display System (GrADS), embedded on WRF upon installation, was used as the default post processing tool.

WRF model is a Numerical Weather prediction (NWP) mesoscale modeling system that is a useful tool in atmospheric research and operational forecast (Skamarock et al., 2008).

\subsection{Methodology}

\subsubsection{Investigation of Aircraft Accident and Incident Data}

In an attempt of the current study to estimate the true number of accidents/incidents against aviation weather hazards that caused them, an excel table was prepared distributing the considered accident or serious incident with the type of aircraft, departure aerodrome, destination, location of accident or incident, date and time of occurrence, and statement on the damage sustained by aircraft and injuries to persons on board. In each of the cases, weather hazard that influenced an accident or incident is appended.

The data was analyzed to determine the relationships between the type of weather hazard cited in the data and accident or incident caused by the hazard. This was summarized in graphical plots.

\subsubsection{Forecasting of Cumulonimbus Clouds}

Several studies globally have used the model (Wang et al., 2009; Ackerman et al., 2009) in their studies used the model for large eddy simulations. In their results they indicated that the model was efficient and that the results were in agreement with the observed data (Ngaina, 2015) evaluated WRF microphysics to simulations of deep convective clouds. The aim of the study was to evaluate the accuracy of the model. The assessment was based on updrafts and downdrafts and total precipitation. From the various studies that have been carried out using the WRF Model, there is a clear indication that the model gives accurate results and can therefore be relied upon.

A case study was conducted on $14^{\text {th }}$ April 2017 to forecast Cumulonimbus clouds. This date was picked to coincide with the month of April, which is the peak of the March- April- May (MAM) wet season. It was expected that at this time of the year, many types of clouds would develop, more so of the convective type. Weather Research and Forecasting (WRF) model was identified as a suitable model for forecasting of cumulonimbus clouds. Cumulonimbus clouds develop under certain favorable conditions, namely: Convective instability, moisture availability and lifting mechanism. 
Surface Convective Available Potential Energy (CAPE) and Lifted Index (LI) at 500mb level were simulated to measure instability of the atmosphere as the parcel of air ascends at each time step.

Relative humidity at $700 \mathrm{mb}$ level was examined since convective processes are best defined at $700 \mathrm{mb}$ within the tropics, with Lifted Condensation Level (LCL) located somewhere within this isobaric surface - the level a parcel becomes saturated when mechanically lifted.

Surface and $700 \mathrm{mb}$ level temperatures were examined alongside the Lifted Index, to determine the vertical gradient of temperature, hence stability and barotropy/baroclinicity of the atmosphere.

Surface winds, and streamline analysis, were useful ingredients in determining the areas of convergence and divergence of air.

Dew point temperature at 2 metres level above the surface was analyzed to tell on the moisture content at the surface.

A nest of the parent domain (Kenya) was created, having its initial boundary conditions as those of Kenya. The nest was used to resolve Mesoscale systems within the Highlands West and East of the Rift valley. This was informed by the climatological zones in Kenya. The length of the forecast was set to $48 \mathrm{hrs}$, so that the model simulation doesn't default to 24 hour.

With the data from GFS downloaded and all settings done, the model was run. The Mathematical and Physical equations of the atmosphere were solved and interpolated to every grid point and then extrapolated to give the future state of the parameters under consideration. The output files were in net.cfd format. It is possible to post process the net.cdf data to other formats, for manipulation. Suitable applications can be used to view and post process the model output. However, Grid Analysis and Display System (GrADS) is embedded on the WRF and upon installation, GrADS becomes the default post processing tool.

\section{Results and Discussion}

\subsection{Weather Hazards to Aviation}

Figure 3 shows the distribution of accidents and incidents over Kenya according to the phase of flight. The figure shows that the accidents and incidents were common when the aircrafts were landing, taking off and during Go-Around/Missed Approach. Other phases of flight cited are Approach and Emergency landing after takeoff due to fog, heavy rain showers, turbulence, and crosswind encounters. The figure tells us that landing is the most dangerous phase of flight.

The figure shows the lowest kilometer of the atmosphere referred to as atmospheric boundary layer where there are more weather activities. The aircraft has come where turbulence is generated as the wind blows over the earth's surface. There is also a possibility of the presence of thermals associated with clouds or generated as a result of uneven heating of the earth's surface by the sun. The pilot having managed coming near the ground may opt to land-set for landing. Landing becomes the appropriate action but the condition of the runway and the weather could cause mishaps.

Sharman et al. (2015) in a study on the effects of rain to aviation noted that torrential rain, due to the effect of poor visibility and flooded runways, has significant effect on airplane in 


\section{Macrothink}

landing configuration. This may explain why landing phase of flight is most affected by weather hazards when compared with other phases.

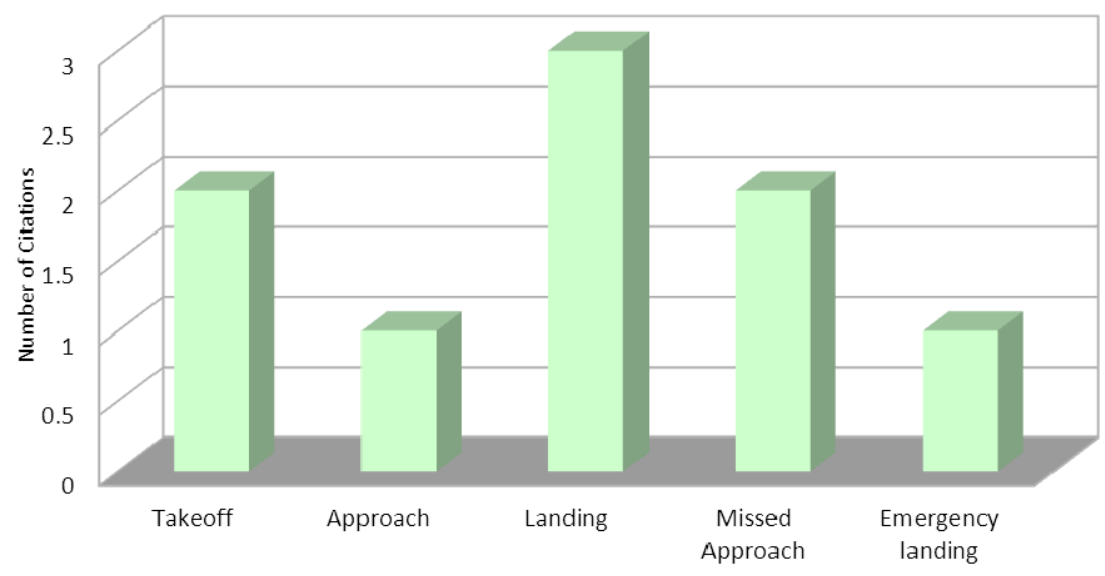

Figure 3. Accidents and incidents citations by phase of flight over Kenyan airspace 2008-2014

Source: KCAA Aviation Accident and Incident Database

\subsection{Simulated Weather Distribution over Kenya}

The results from the simulation using the Weather Research and Forecasting (WRF) Model are discussed in this section. The weather parameters analyzed include Wind at $10 \mathrm{~m}$ level, Surface temperature, Lifted Index (LI) at 500mb level, Convective Available Potential Energy (CAPE), Relative Humidity (RH) at $700 \mathrm{mb}$ level, and Dew point temperature at $2 \mathrm{~m}$ level.

Figure 4 shows the $1200 \mathrm{Z}$ Surface temperatures drawn together with the $10 \mathrm{~m}$ winds. From the figure, the surface winds are predominantly South Easterlies over most parts of the country. The winds converge over the central and western highlands. The temperatures are high over the Coast, Eastern and North Western sectors of the country, and low over the western, southwestern and central parts of Kenya. From the figure, it is noted that enhanced surface convergence is witnessed over the high ground areas. The wind convergence is giving us the lifting mechanism. If other conditions are available we should expect the area to be active. 


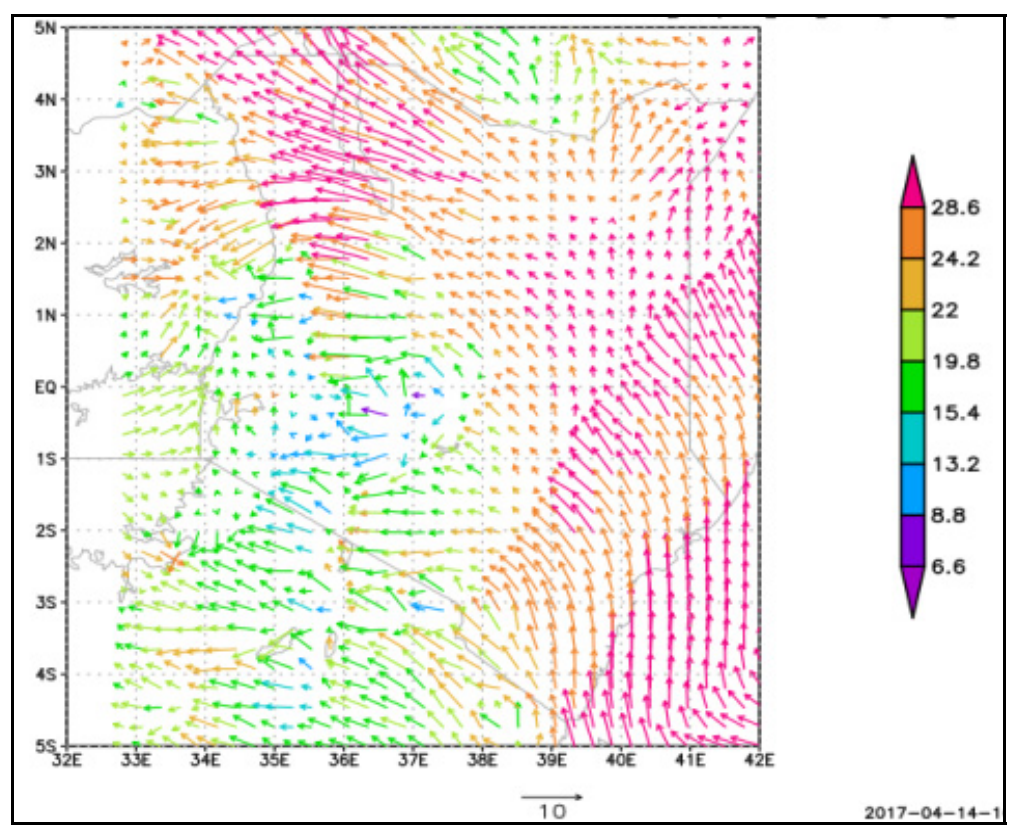

Figure 4. 12Z Surface Temperatures superimposed on $10 \mathrm{~m}$ winds

Source: WRF model run on the 14-04-2017

Figure 5 shows Lifted Index at $500 \mathrm{mb}$ level. Values between -4 degrees to -6 degrees would favor thunderstorm development; negative 6 degrees of LI or lower, usually yields severe thunderstorm; and Positive values of LI imply no major convective development. From the figure, most of the places, especially over the western half of the country, had LI indices above $0^{\circ} \mathrm{C}$. This implied stability, with minimal activities at this particular hour over the western part of the country. Much of the eastern half had negative indices, suggesting that the region would benefit from convection instability.

Lifted index shows that the static stability was generally stable despite the convective mechanism over a large area. The mechanism is there but we can also see the convective energy is low. This could be attributed to low temperatures over the region. 


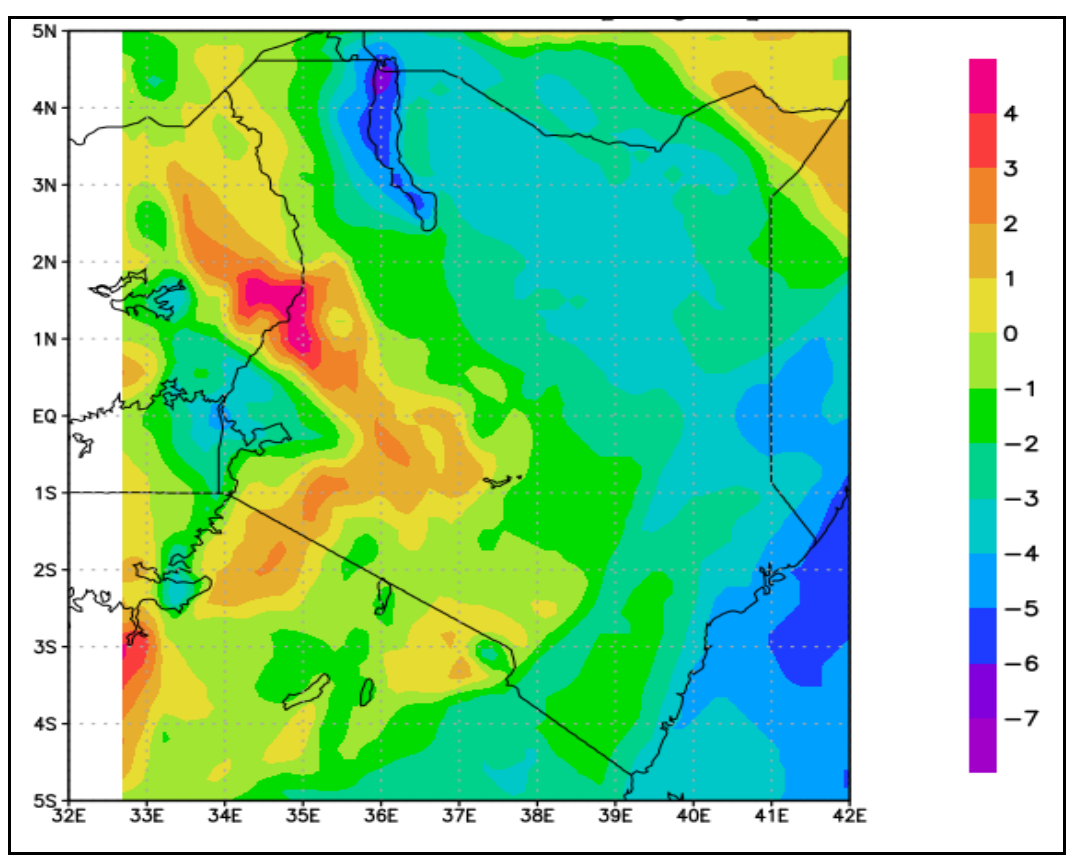

Figure 5. 500mb level lifted index

Source: WRF model.

Figure 6 shows the distribution in space of the Convective Available Potential Energy (CAPE). From the figure, most places over the central and western parts of the country were stable at this hour. We see that these areas with less trigger mechanism have higher convective energy. CAPE gives us energy of the whole depth which is telling us that most of the areas did not have convective potential energy. 


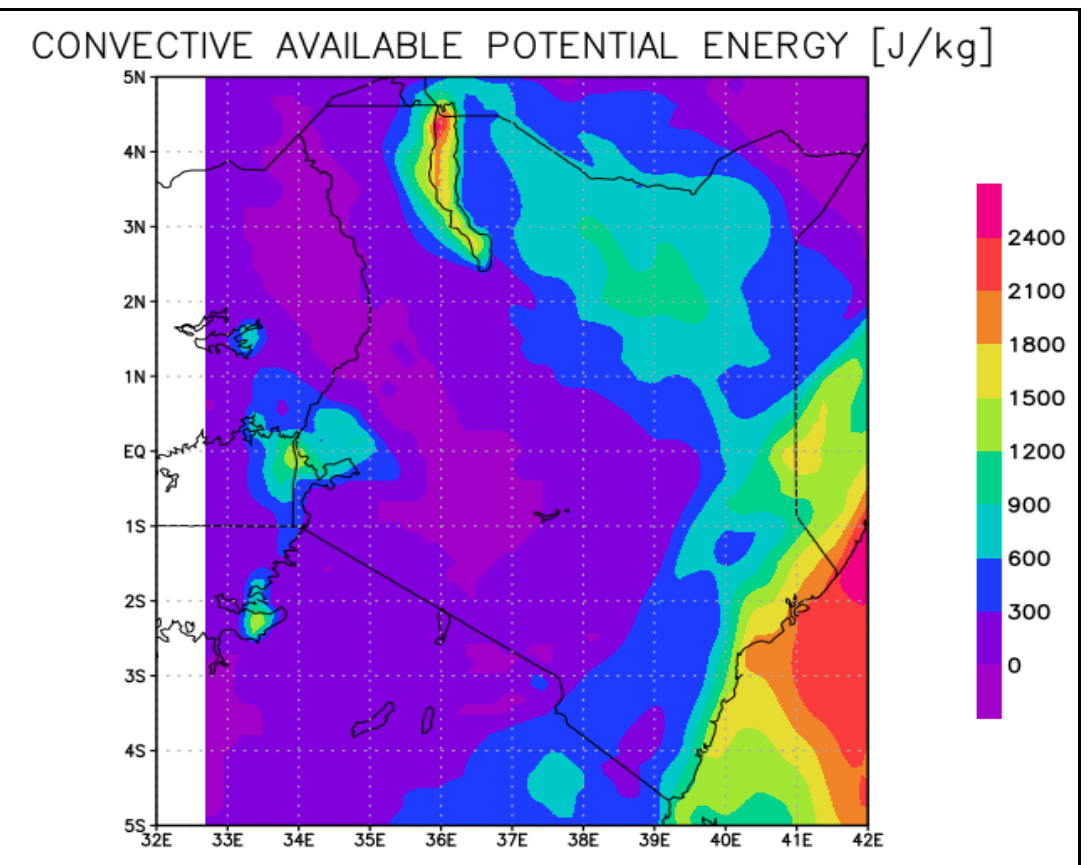

Figure 6. CAPE

Source: WRF model.

Figure 7 shows relative humility profile at $700 \mathrm{mb}$ level. Relative humidity was generally above $50 \%$ over most parts of the country, hitting $80-100 \%$ over the western and central and northern parts of the country. These values, especially over the western, central and northern parts, should supply sufficient moisture. There seems to be more supply over the lake region while other areas are generally low- there was less moisture supply over most parts of the country. 


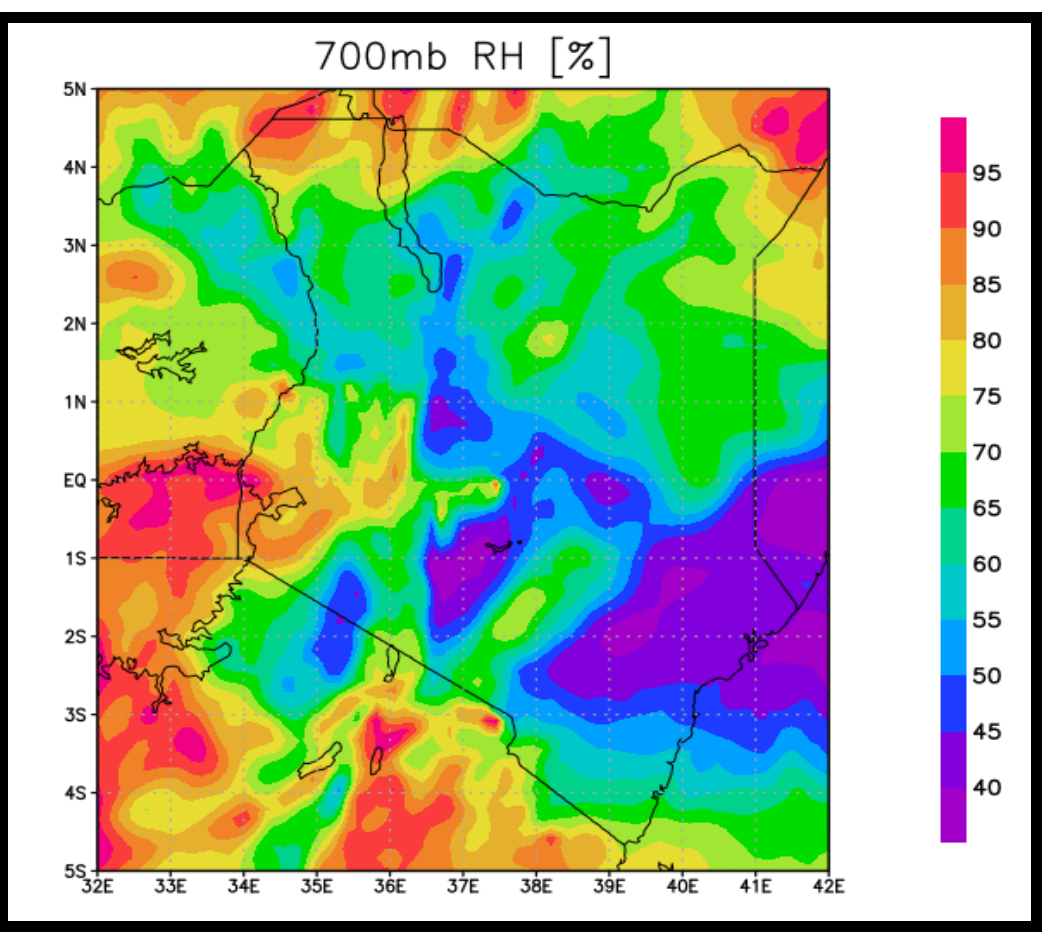

Figure $7 . \mathrm{RH}$ at $700 \mathrm{mb}$

Source: WRF Model.

Figure 8 shows the contours of dew point temperatures at $2 \mathrm{~m}$. Dew point temperature is a measurement of low-level moisture content. The distribution map shows high values of dew point temperature on the eastern parts of the country and relatively low values on the western parts. The lower the value of the dew-point temperature the lower the saturation state of the air. From the figure it can be seen that at this time, the eastern part of the country had relatively higher values, with the western half of the country reporting lesser values.

It therefore implies that the western part of the country is less humid and the eastern region more humid. At the surface the lower the dew point the lower the moisture- the higher the dew point the higher the moisture. 


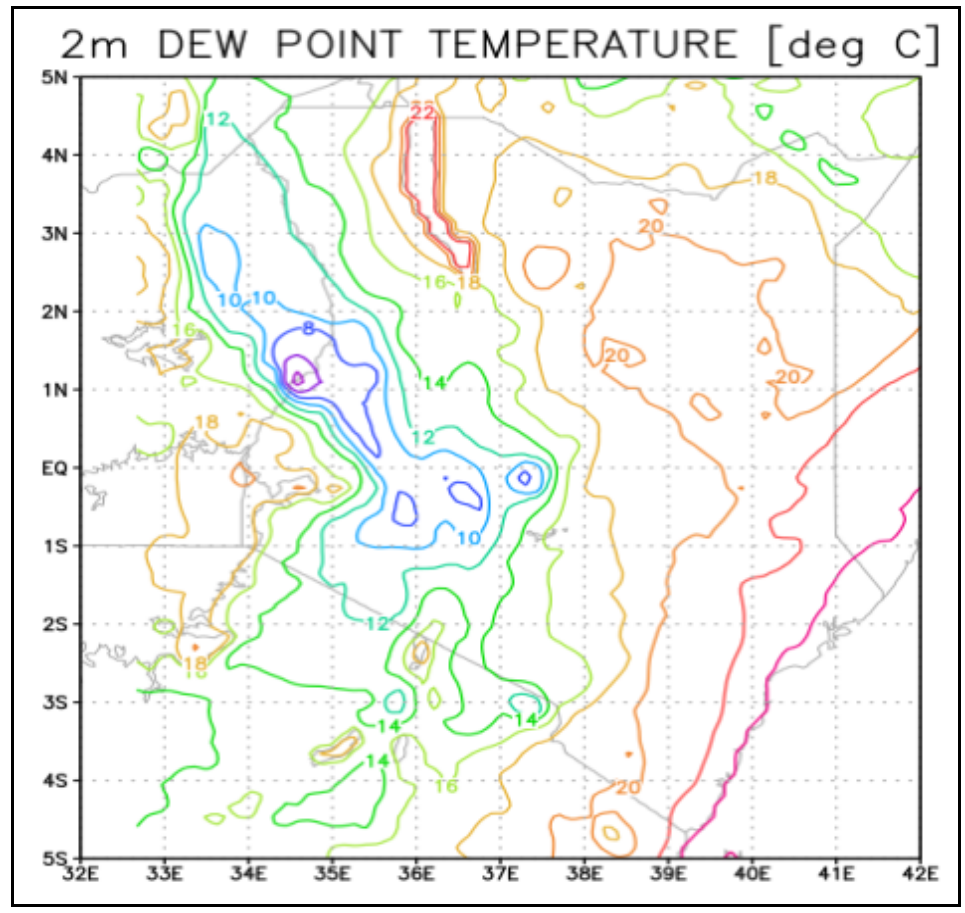

Figure 8. 2m Dew Point Temperature

Source: WRF model.

The parameters that are aforementioned are useful in identifying areas where aircraft weather hazards occur over Kenya. What was observed is agreeing with the indices in the model thus telling us the model can identify these hotspots. We have seen that generally areas of cumulonimbus clouds are limited.

Where there was strong lifting mechanism, moisture was deficient and where moisture was available the lifting mechanism was slightly weaker. Wind patterns tell us the areas where hazards are likely to occur. Based on the winds, the wind convergence is giving us the lifting mechanism. Most areas did not have convective potential energy which is supported by the lifted index. The cold environmental temperature seemed to have lowered the static instability.

Energy is a function of moisture and if the dew point temperature is low we have to raise moisture to a higher level since the Level of Free Convection (LFC) is high. We need to lift the parcel of air until this level is attained to enable it to have buoyancy to rise on its own. The area to be integrated between the level of free convection and the equilibrium level is high hence the area of CAPE is small-convective available potential energy is small. This is the positive buoyant energy which is the buoyant heat a parcel of air has between Level of Free Convection (LFC) and Equilibrium Level (EL).

There are areas where conditions of potential are available but it lacks a push due to diffluence- trigger mechanism was lacking in such regions. We have to combine the potential, trigger mechanisms, and moisture cumulatively. The accumulated effect seem to point that we should expect intense activity over the lake region as is informed by the cloud imagery on figure 9.It shows that if we assimilate the parameters even without the cloud imagery they 


\section{Macrothink}

should tell us what to expect. These various parameters when analyzed we should be able to identify the hotspots.

The widespread coverage of clouds and increase of cloud types during the wet season with minimum activity may be due to lack of potential convection and other conditions are not enhanced. When all the parameters were put together they were able to give us the resultant which is the type of clouds we are looking for- the amount of clouds that covered the sky was ranging from 1 to 2 octas (few) over the lake. Nevertheless the aim was to see whether the combination of the parameters could identify the areas. The areas where they agree is over the lake region where we observe cumulonimbus clouds. This is confirmed with the cloud image shown below.

Figure 9 shows the China based Geostationary Fengyun 2E (FY2E) satellite cloud genera over the area of current study. The figure places most convective cloud types, majorly over the western region of the country, just as the model had captured.

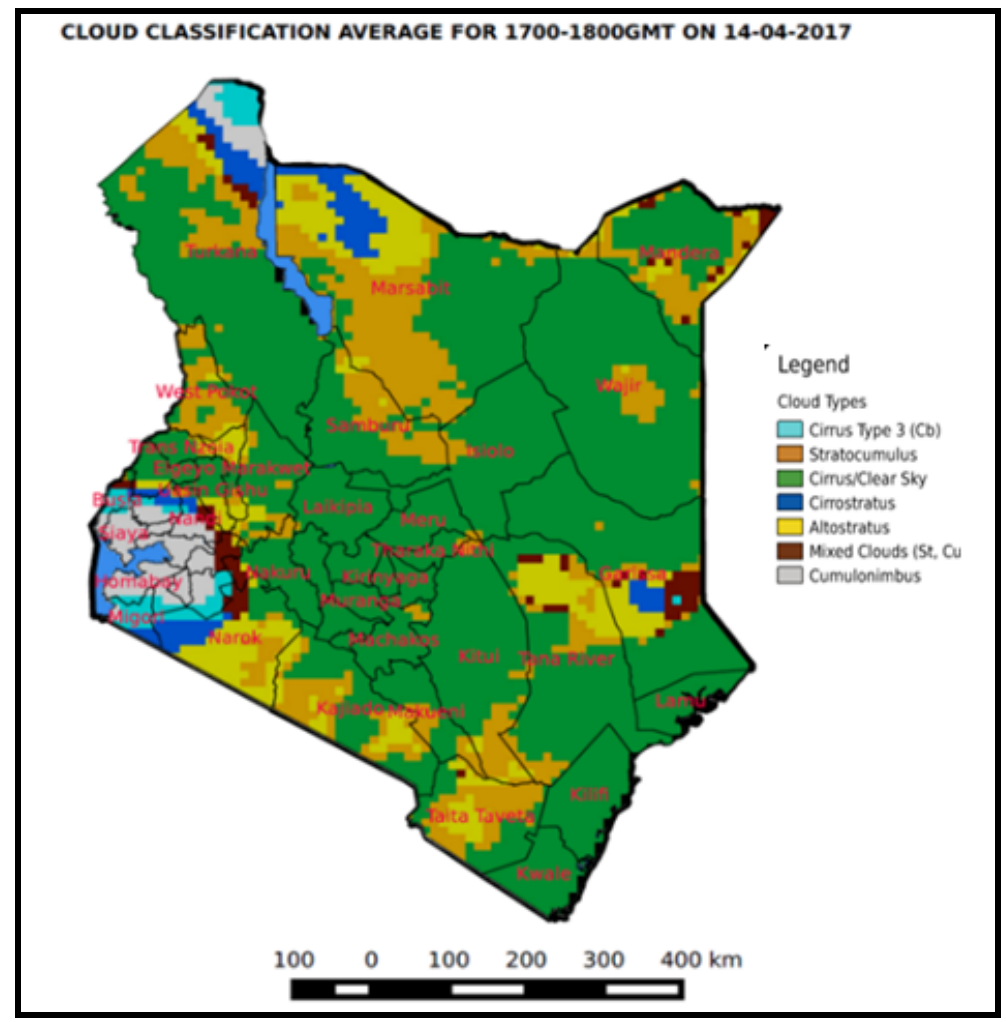

Figure 9. Cloud classification averaged between 1700 and 1800 UTC on 14-04-2017 Source: FY2E Satellite.

\section{Conclusions and Recommendations}

\subsection{Conclusions}

The study showed that Highlands West and East of the Rift Valley experienced most clouds most parts of the year. The frequencies of the most dangerous clouds are observed over these regions. The result from the simulation using Weather Research and Forecasting (WRF) Model showed that the parameters such as Winds at $10 \mathrm{~m}$ level, Surface temperature, Lifted 
Index (LI) at 500mb level, Convective Available Potential Energy (CAPE), Relative Humidity $(\mathrm{RH})$ at $700 \mathrm{mb}$ level, and Dew Point Temperature at $2 \mathrm{~m}$ level can be used to identify the areas where the particular clouds occur.-when we combine them they are able to tell us the area of convection and hence provide the means of prediction.

\subsection{Recommendations}

\subsubsection{To The Aviation Sector}

The hotspot areas have been identified. The study has shown that most of the cumulonimbus clouds are frequent over the routes to the main destination of the local flights. They can however avoid the weather hazards if the planners properly schedule their flights at the time when we have more likelihood of cumulonimbus clouds.

\subsubsection{To Researchers}

In the current study the hotspot areas were identified in respect to cumulonimbus clouds but we also need a map to mark other areas in respect to other hazards. The China based Geostationary Fengyun 2E (FY2E) satellite was used to identify and classify the clouds during wet and dry seasons over the study area and the Meteosat Second Generation (MSG) Infrared 10.8 satellite was used to determine the cloud temperatures and areas where there were deep convective clouds - development of convective cells were easily identified.

The results from the two tools were in agreement however we need facilities for characterization of clouds to be obtained for finer details - the Fengyun in certain cases could not give finer details and a number of clouds were grouped as mixed clouds.

\subsubsection{To The Kenya Meteorological Department}

The department needs to invest into modeling by training more personnel in modeling; to buy high speed computers; and to invest into data initialization (regional data analysis) on finer resolution. In order to achieve this they need to improve the grid to provide information not only to pilots but also to other users.

They can undertake pilot observation to help improve in the data resource because there are many things that happen on mesoscale that we cannot capture on synoptic scale. They can undertake intense network for 6 months or 1 year and use the data in improving the analysis. This would enable them to capture the patterns that occur to be able to capture sub-synoptic scale features.

The study has demonstrated the potential of the model and I recommend that the department take a step and it becomes operational.

\section{References}

Ackerman, A. S., Van Zanten, M. C., Stevens B., Savic-Joycic, V., Bretherton, C. S., Chloud, A., ... Zulauf, M. (2009). Large-eddy Simulations of a drizzling, Stratocumulus-topped Marine boundary layer, Mon. Weather Rev, 137, 1083-1110. https://doi.org/10.1175/2008MWR2582.1

ICAO (International Civil Aviation Organization). (2001). International Standards and Recommended Practices. Annex 13 to the Convention on International Civil Aviation. Aircraft Accident and Incident Investigation.

Ngaina, J. N. (2015). Modeling Aerosol-Cloud Precipitation Interactions for Weather 
Modification in East Africa Ph.D.Project Report. Department of Meteorology.

Okoola, R. E. (2005). Aeronautical Meteorology (SMR 312) (pp. 42-49). University of Nairobi Press.

Sharman, H., Harshe, S., Vekaria, S., Singh, M., Damodaran, M., \& Beo, C. K. (2015). Computational Assessment of Rainfall Effects on Aircraft Aerodynamic Characteristics. 33rd AIAA Applied Aerodynamics Conference. https://doi.org/10.2514/6.2015-3164

Skamarock, W. C., Klemp, J. R., Dudhia, J., Gill, D. O., Barker, D. M., Duda, M., ... Powers, J. G. (2008). A description of advanced research WRF Version, 3: 53. NCAR. Tech. Note.

Wang, H., \& Feingold, G. (2009). Modeling Mesoscale Cellular Structures and Drizzle in Marine Stratocumulus Part 1: Impact of Drizzle on the Formation and Evolution of Open Cells. Journal of the Atmospheric Sciences, 66(11), 3237-3256. https://doi.org/10.1175/2009JAS3120.1

\section{Copyright Disclaimer}

Copyright for this article is retained by the author(s), with first publication rights granted to the journal.

This is an open-access article distributed under the terms and conditions of the Creative Commons Attribution license (http://creativecommons.org/licenses/by/3.0/). 